\title{
Draw your story: Exploring adaptation experiences of first-year students at the institute of teacher education in Malaysia
}

\author{
Tengku Norhani Tengku Besar ${ }^{1}$, Nor Shafrin Ahmad², Shahabuddin Hashim ${ }^{3}$, Siti Salina Abdullah \\ ${ }^{1,2,3}$ School of Educational Studies, Universiti Sains Malaysia, Pulau Pinang, Malaysia \\ ${ }^{4}$ Faculty of Business, Economics and Social Development, Universiti Malaysia Terengganu, Terengganu, Malaysia
}

\section{Article Info \\ Article history: \\ Received Dec 15, 2020 \\ Revised Jun 28, 2021 \\ Accepted Jul 19, 2021}

\section{Keywords:}

Adaptation

Drawing

First-year student

Storytelling

Transition

\begin{abstract}
The transition from school to the institute of higher learning is a challenging phase that requires students to adapt to new environments and cultures. This study aimed to explore the adaptation experiences of first-year students at the Institute of Teacher Education by using storytelling through drawing. This study involved 18 students pursuing the Bachelor of Education Preparatory Programme at the Institute of Teacher Education in Malaysia with low levels of adaptation identified through Student Adaptation to College Questionnaire (SACQ). The qualitative data were analyzed using thematic analysis. Findings showed that the first-year students at the Institute of Teacher Education experiencing adaptation challenge in four main themes: academic, social, personal, and interest. The findings of this study are expected to contribute towards the formation and development of appropriate interventions to assist the well-being of first-year students at the Institute of Teacher Education, Malaysia, in adapting to the new environment.
\end{abstract}

This is an open access article under the CC BY-SA license.

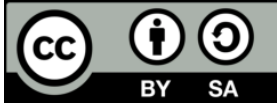

\section{Corresponding Author:}

Tengku Norhani Tengku Besar

School of Educational Studies

Universiti Sains Malaysia

11800 Penang, Malaysia

Email: tengkunorhani77@gmail.com

\section{INTRODUCTION}

Every student has high expectations when furthering their studies at institutes of higher education (IHE). They are going through a phase of transition from school to IHE where there are many challenges to go through. The process of adapting to the new academic system, academic environment and social environment may not be easy to some students, while others may take a long period of time to get adjusted. Thus, their ability to meet the challenges and have a good relationship with the institute of study [1], [2] is an indication of students' adaptation. This can also be observed through their attitude towards the courses they enrolled in, their involvement in learning and efforts made while learning [3] and have good academic performance [4]. Students need to act or behave in accordance with the changing environment. If they fail to adapt to the changes in the environment, these conditions will affect their well-being and reduce the chances of resilience [5].

The issue of student adaptation has received a considerable critical attention. The process of adapting to the new life on campus forces students to go through a psychological process to adapt, address, and manage various issues such as social, personal-emotional and closeness with IHE [6] effectively on various challenges that arise in the environment new at IHE [7]. Based on past studies, several constructs have been identified in relation to university adjustment such as anxiety, stress vulnerability, anger, mood, mental illness, indicative for negative adaptation [8]. In addition, Ababu, et al. [9] found four categories of 
problems that make it difficult for students in local universities to make adaptation, namely academic problems, health problems, financial crises, social and personal problems. This situation can cause students fail to complete their studies.

The past thirty years have seen that the transition from school to IHE puts pressure on students but their ability to deal with that stress is based on their personal adaptability [10]. First year students face a very stressful experience during a few days on campus and this stress continues as the semester progresses [11]. Elias, Wong, and Abdullah [3] argued that the adaptation of students to higher education is complex because it involves demands of various types and levels. Thus, students need a variety of strategies to deal with. Previous studies have reported that integration between the new and old environments and the time taken for individuals to become comfortable with the new environment is determined by individuals' personal characteristics, past experiences, and needs [12]. In other words, the transition process needs to be seen in an individual context. Moreover, the transition to IHE involves building an understanding of the new environment and how the new environment works [13]. For this reason, students encounter challenges when they start registering at IHE. Transition experiences will change, while the feelings of loneliness and anxiety over these challenges are common for new students in the first week at IHE. Therefore, the transition to institutes of higher learning is very complex. The transition also requires students to create a new identity as higher education students [14].

Studies related to the adaptation of first-year students in the institutes of higher learning are not a new, be it at the international level or in Malaysia. In fact, there are numerous studies related to student adaptation. The ability to adapt to college life and stay there is sometimes affected by academic, nonacademic, social, and logistical challenges. Among the challenges are relationships with family members and friends, building relationships with the college community, overcoming isolation, stress, depression and anxiety, finances, health, interpersonal skills, difficulty adjusting to changes, developing personal autonomy, making important career-related decisions, and status residence [15]. Past studies have also reported that students experienced confusion due to their transition to college [7], [16]. As a result, students were found to be facing academic difficulties [17], emotional problems such as isolation, loneliness, stress and depression [18], strained relationships with family members and classmates [19], the issue of substance abuse [20] which eventually caused them to be expelled from school or college [7].

The problem of adaptation is not only common among students at the university, but this is also faced by students at the Institute of Teacher Education Malaysia (ITEM). The study of Chiam [21] found that adaptation problems affected mathematics achievement among trainee teachers of the Bachelor of Teaching Preparation Program (PPISMP) at ITEM. Emotional personal circumstances were a major factor reported to have disrupted the process of academic adjustment of trainee teachers and social adjustment during institutional transition. In addition, the statistics released by ITEM Sarawak showed that the percentage of students who dropped out of training was 0.89 to $4.35 \%$ between 2012 to 2015 [22]. Although extensive research has been carried out on student adaptation, most researchers have focused on university students [18], [23], [24]. In fact, there are limited qualitative studies conducted on students' adaptation experiences. Hence, an in-depth study is much needed to explore the adaptation experiences of first-year students at ITEM to obtain crucial information necessitated for appropriate interventions.

For this purpose and to help students express their adaptation experiences, the application of art therapy and narrative therapy can help students externalize the experiences [25]. Furthermore, this approach can identify the problems of group members when they visualize the problem [26]. Thus, to help group members externalizing the problems, storytelling techniques are used. Group members will tell stories through drawings of the experiences that bother them. Through the interactive process of storytelling and art making (drawing), individuals can integrate their senses, feelings and behaviors. Moreover, individuals can explore personal narratives safely. In addition, narrative exploration gives individuals the opportunity to experience their lives. Storytelling offers a means for imparting wisdom and legacy leaving. In other words, art therapy provides a framework where personal narratives can be developed and explored [27]. Storytelling allows students to expand the imagination of their experiences and enrich their ability [28] to express what they are going through. Thus, this study was carried out to explore the adaptation experiences of first-year students at the Institute of Teacher Education Malaysia.

\section{RESEARCH METHOD}

This research applied a qualitative design with the aim to explore the adaptation experiences of firstyear students at the Institute of Teacher Education Malaysia using storytelling through drawing approach. The study involved 18 first-year students of the Bachelor of Teaching Preparation Programme at the Malaysian Institute of Teacher Education aged 18 years selected via purposive sampling. They were selected based on the low score on the Student Adaptation to College Questionnaire (SACQ). SACQ has been used to 
measure students' level of adjustment. The questionnaire used a compiled Likert scale of 1 to 9 based on a low degree of adaptation to a high degree of adaptation. Score 9 represents the answer "Closely related to me" while score 1 represents "Not related to me". Cronbach's alpha reliability test for this instrument reached a good level of above 0.70 [29] of 0.90. This study only involved overall student adaptation scores. According to Arjanggi and Kusumaningsih [1], the overall adaptation score indicates the level of student adaptation. The total overall adaptation score which is below the total mean score of 360 indicates the level of adaptation is low. Details of the students are summarized in Table 1.

Table 1. Details of students

\begin{tabular}{cccccc}
\hline Code & Age (years) & Sex $(\mathrm{M} / \mathrm{F})$ & Race & Course & SACQ score \\
\hline S1 & 18 & F & Malay & Islamic studies & 335 \\
S2 & 18 & F & Malay & Islamic studies & 346 \\
S3 & 18 & F & Malay & Guidance and counseling & 329 \\
S4 & 18 & F & Malay & Guidance and counseling & 352 \\
S5 & 18 & M & Malay & Malay language & 338 \\
S6 & 18 & F & Malay & Islamic studies & 305 \\
S7 & 18 & F & Malay & Islamic studies & 341 \\
S8 & 18 & F & Malay & Malay language & 335 \\
S9 & 18 & F & Malay & Islamic studies & 326 \\
S10 & 18 & F & Malay & Islamic studies & 343 \\
S11 & 18 & F & Malay & Malay language & 351 \\
S12 & 18 & M & Malay & Islamic studies & 349 \\
S13 & 18 & F & Chinese & Guidance and counseling & 341 \\
S14 & 18 & F & Chinese & Guidance and counseling & 348 \\
S15 & 18 & F & Chinese & Guidance and counseling & 348 \\
S16 & 18 & F & Chinese & Guidance and counseling & 334 \\
S17 & 18 & M & Chinese & Guidance and counseling & 354 \\
S18 & 18 & M & Malay & Islamic studies & 346 \\
\hline Note: S= Student M=male; F= female & & &
\end{tabular}

Group counselling sessions were conducted for students with low levels of adaptation. Prior to the counseling session, the students were briefly explained about storytelling through drawing approach. Then, warming up activity was done to get them familiarized with drawing paper and crayon colors. The students also asked to express their feelings in the present. This was followed by asking the students to draw their adaptation experiences freely after a month in ITEM. The drawing session took around 20 minutes. Later, they were asked to share the story based on their drawing. The step approach is summarized in Table 2.

Qualitative data were obtained from the participants' narrative video recordings based on their drawings. The data were analyzed using the analytical procedures suggested by Braun and Clarke [30] to identify the themes. These involved five phases of getting familiarized with the data, generating initial codes, searching for themes, reviewing themes, defining, and naming themes and producing the report.

Table 2. Step approach

\begin{tabular}{|c|c|c|}
\hline Step & Activities & Instructions \\
\hline Step 1 & $\begin{array}{l}\text { Building and establishing } \\
\text { rapport }\end{array}$ & $\begin{array}{l}\text { Students were given an explanation on storytelling through drawing. Students were } \\
\text { also made to fully understand instructions. The facilitator showed some examples } \\
\text { related to the activity. }\end{array}$ \\
\hline Step 2 & Warming-up session & $\begin{array}{l}\text { Students were asked to draw their feelings at the moment. Then, the students were } \\
\text { asked to share their feelings by telling a story based on the drawings. This activity was } \\
\text { to ensure they became familiarized with the use of crayon colors and drawing paper. }\end{array}$ \\
\hline Step 3 & $\begin{array}{l}\text { Let's draw your story } \\
\text { Materials needed: Drawing } \\
\text { paper and crayon color }\end{array}$ & $\begin{array}{l}\text { Students were asked to draw on their month-long experiences at ITEM. They were } \\
\text { asked to express their adaptation experiences freely. (Theme is not set. Students } \\
\text { express their adaptation experiences freely) }\end{array}$ \\
\hline Step 4 & Story sharing time & $\begin{array}{l}\text { Students shared the stories of their adaptation experiences with each other based on } \\
\text { their drawings. }\end{array}$ \\
\hline
\end{tabular}

\section{RESULTS AND DISCUSSION}

Thematic analysis revealed a list of adaptation experiences by 18 students in their first-month experiences at the Institute of Teacher Education Malaysia. These experiences were clustered into four main themes: experiences of adaptation in academics, experiences of adaptation in social, experiences of adaptation in personal and experiences of adaptation in lack of interest. Figure 1 presents these themes and their emerging categories. 


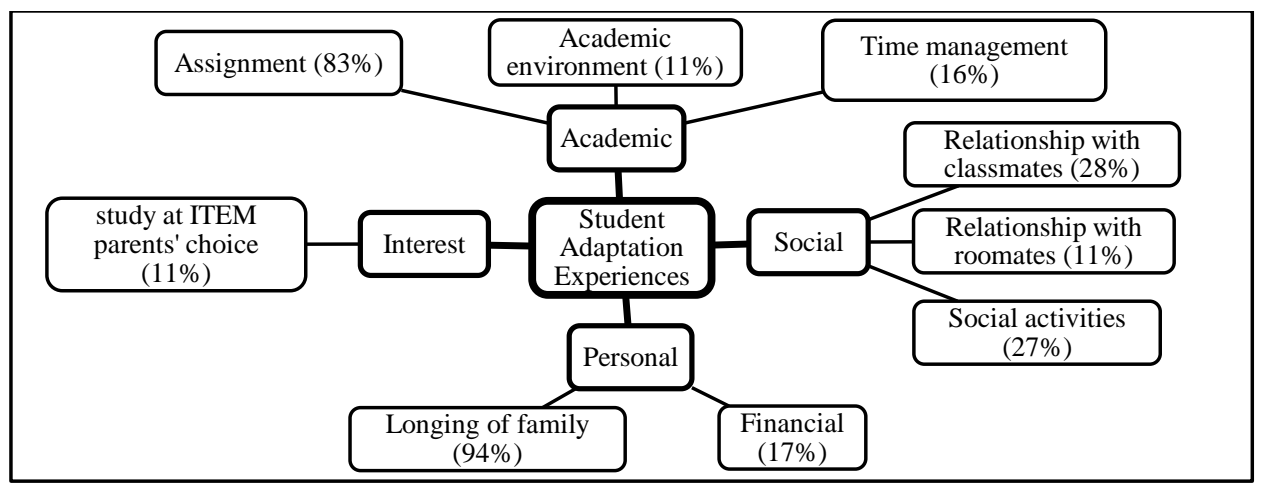

Figure 1. A thematic map of the students' adaptation experiences (Percentages in brackets represent the frequency of subtheme endorsement)

\subsection{Academic}

Findings show that students have difficulty in making academic adjustments. In this study, academic adjustment is one of the major problems among the students. The study found that the difficulties in academic adjustment experienced by students are further divided into three main areas, namely academic assignments, academic environment, and time management. This finding is in line with the findings of some previous researchers who reported that students with adjustment problems would experience academic difficulties such as understanding assignments and study time management [17].

\subsubsection{Academic work}

The findings of the study indicated that the students experienced stress in adapting and understanding academic assignments which turned out to be different from academic assignments in school. The students also found it difficult to complete their assignments because this was the first time for them. In fact, the students felt there was not enough time to complete many academic assignments. As for a participant with health problems, she was stressful because she needed to complete academic assignments and this had an impact on her health. In addition, students still relied on family members to do their assignments. They were so used to being assisted by family members while completing schoolwork. Studying at ITEM, however, they needed to be independent in doing academic assignments. Some felt stressful because the process of understanding their academic assignments differs from their school assignments. Drawing images relating to the experiences of difficulties in academic assignments are given in Figure 2 and Figure 3.

"I feel stressed. That course works... SEGAK test course work I must push myself to do push-ups. I will be in pain when I do. If I get sick, I just lie on the bed. Indeed, if it hurts, you can't do anything. You can't even eat," (S18/2, lines 2-6, 08/10/2020)

"So, when doing an English assignment, it's stressful too. Because if at home, my sister will help," (S1/2, lines 3-4, 08/10/2020)

"My problem is assignment. Time is also not enough. Speech online I do not know how to do. Because for the first time. Lots of mistakes" (S17/2, lines 1-2, 08/10/2020)

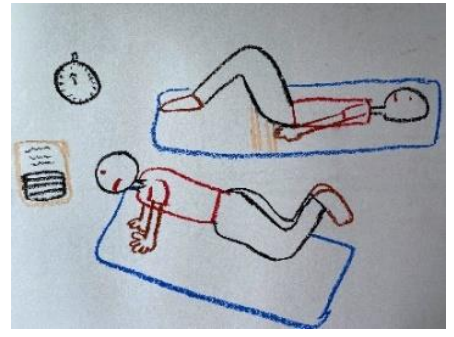

Figure 2. Drawing S18/2, 08/10/2020

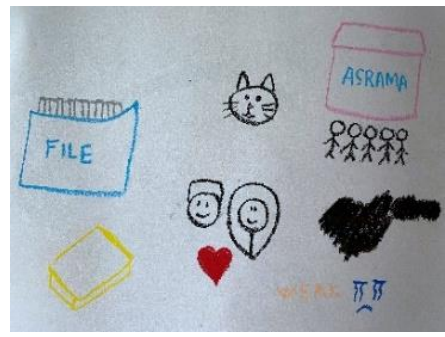

Figure 3. Drawing $S 1 / 2,08 / 10 / 2020$ 


\subsubsection{Time management}

In addition, the findings also indicated that the students experienced difficulties in time management. The transition from the school system to the ITEM system has apparently caused the participants to struggle in managing their time. For the participants who had never lived in a hostel, they faced difficulties in managing the time between lecture time and time to complete academic assignments. Some students drew a clock symbol that showed their time management. One of the students responded that it was difficult to manage time well because he had never lived in a hostel. Drawing images related to students' time management challenge experiences are shown in Figure 4 and Figure 5.

"I'm not good at managing time," (S6/2, lines 3-4, 08/10/2020)

"I think I am not good at managing my time properly" (S4/2, line 1, 08/10/2020)

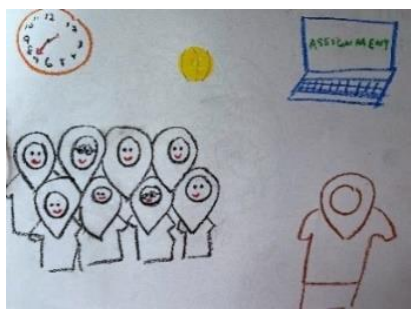

Figure 4. Drawing S6/2, 08/10/2020

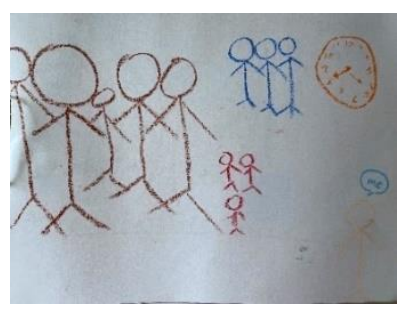

Figure 5. Drawing S4/2, 08/10/2020

\subsubsection{Academic environment}

Another pertinent finding of this study is that the students experienced difficulties in adapting to the new academic environment, especially one involving changes in language use. One student said:

"My problem in the academic field. Mathematics. Because I used to learn mathematics in English, now need to learn Mathematics in Malay language. That's a challenge for me," (S16/2, line 1-2,08/10/2020)

A major implication of this concerns students' use of time in completing their academic assignments. In addition, since the teaching and learning is mostly held online because of the COVID-19 pandemic, it is difficult for the students to adapt and understand the lessons delivered by the lecturers. This is in line with Matamit, et al. [29], i.e., first-year students at the higher institution have difficulty adapting to the teaching styles at the institution of higher learning than at school. The students' experiences were expressed in the form of drawings such as Figure 6 and Figure 7.

"Then, assignment. I prefer to study face to face. So, when studying online, I find it difficult to understand," (S3/2, lines 3-4, 08/10/2020)

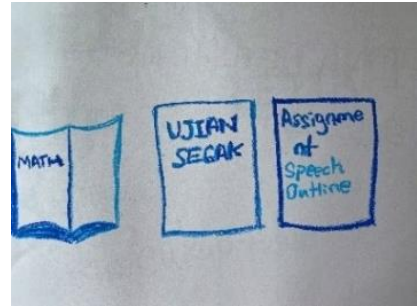

Figure 6. Drawing S16/2, 08/10/2020

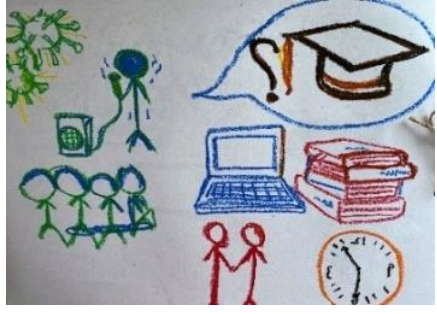

Figure 7. Drawing S3/2, 08/10/2020

\subsection{Social}

The findings of the study also revealed that the students had difficulties in social adjustment. The students' social adjustment experiences were categorized into three themes: relationships with classmates, roommates, and social activities. The quality of social relationships is strongly related to students' adaptation during the transition throughout the first year at ITEM [30]. 


\subsubsection{Relationship with the classmates}

In addition, the study found that the students faced difficulties in adjusting with their classmates. They experienced issues in relationships with their classmates, feelings of being sidelined by their peers, the feelings of dislike, and conflicts of personalities. These findings support the results of previous researchers who reported that students with social adjustment problems tended to have strained relationships with classmates [19]. One of the participants expressed that this condition affected her such as the feelings of loneliness and being alone. This result is in line with Wintre, et al. [18] who stated that students with social adjustment difficulties experienced emotional problems such as isolation, loneliness, stress, and depression. Drawing images related to students' difficulty adjusting with classmates are as in Figure 8 and Figure 9.

"Then there was a problem with my classmate... So, I know this person does not like me," (S5/2, lines 12-15, 08/10/2020)

"I was sidelined by friends... I talked to them. But they just stared and kept walking away. After that, I just found out that they really want to set me aside," (S10/2, lines 4-9, 08/10/2020)

"The second is my problem with my friend. My classmates. Sometimes the way he spoke made me feel sad. Because he seems to be angry with me. I feel sad, lonely, alone" (S17/2, lines 2-4, 08/10/2020)

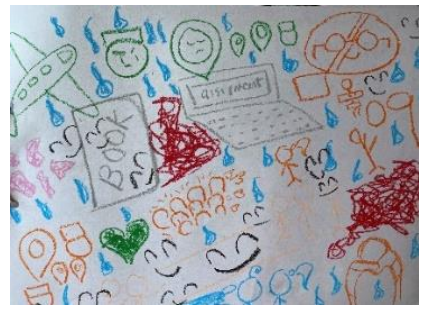

Figure 8. Drawing S10/2, 08/10/2020

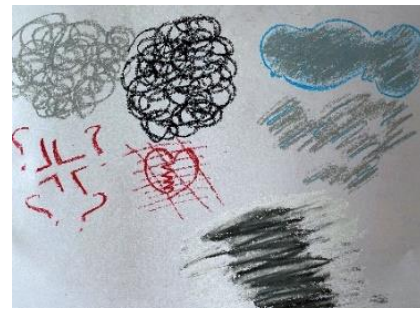

Figure 9. Drawing S5/2, 08/10/2020

\subsubsection{Relationship with roommates}

Meanwhile, the students also had difficulties adapting to roommates of different backgrounds, cultures, and personalities. This situation caused discomfort in staying in a room and caused the participants to stay in another friend's room. Based on findings of some previous studies, researchers emphasized that students who are sociable, share similar opinion, open-minded and have stable emotions can easily adjust by building new social relationships [7], [31]. Self-image was separate from a group of friends as shown in Figure 10 and Figure 11 is described as the symbol of having difficulties adjusting to roommates.

"I have a problem with my roommate. My roommate ... I can't see things that are not organized. She's a little dirty. I can't live in that situation. So, I always seem to leave the room. At night I hang out in my friend's room. (S4/2, lines 4-6, 08/10/2020)

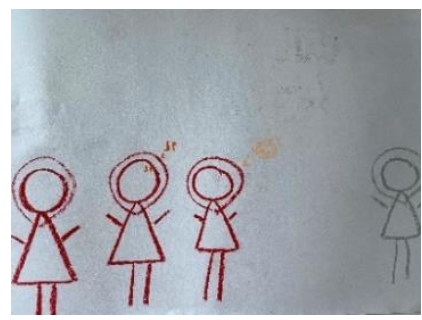

Figure 10. Drawing S9/2, 08/10/2020

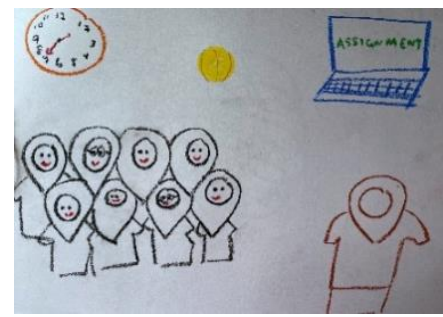

Figure 11. Drawing S4/2, 08/10/2020

\subsubsection{Social activities}

Other findings also showed that the students were not satisfied with the social activities held. The students at ITEM are required to engage in curriculum and co-curricular activities as part of the training to 
prepare them as teachers. Students with social adjustment difficulties will feel disturbed by the social activities. The current study found that the students also faced communication problems and considered the problem as a big challenge. This is also in line with the findings of some previous studies, whereby the students with social adjustment difficulties were reported to experience feelings of loneliness, anxiety, and lack of positive relationships with others [32]. Self-image away from the group is related to the difficulties of communicating with others as shown in Figure 12.

“Third, handball. Because it feels like being forced," (S4/2, line 2, 08/10/2020)

"I'm not good at communicating with people. So, I don't have many friends... I think the problem that is not good at communicating is the tiger. Can eat myself anytime," (S6/2, lines $1-8,08 / 10 / 2020)$

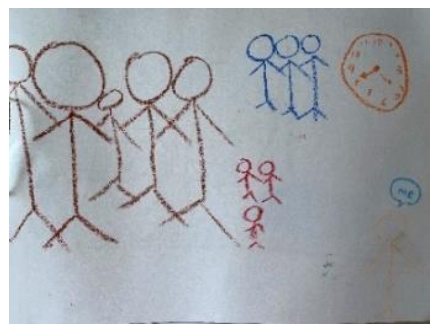

Figure 12. Drawing S6/2, 08/10/2020

\subsection{Personal}

The findings of the study also found that students have difficulty adapting to the new environment due to longing for family and home. In addition, the findings of the study indicated that student also experienced financial problems.

\subsubsection{Longing for family and home}

The findings of the study also showed that the students experienced the feeling of longing for family and homesick. After a month at ITEM, they were not allowed to return home on the orders of the Movement Control Order by the government due to the COVID-19 pandemic. Family members were also not allowed to visit them. Thus, the students experienced the feeling of longing for family and homesick. The findings of the study also revealed that the students kept wondering when COVID-19 would end so that they could return home. This finding is in line with previous researchers [1], [33] that first-year students tend to experience feelings of longing for family. This feeling of longing makes it even more difficult for students to adapt to the new environment. Drawing images related to students' feeling of longing for family and homesick are as in Figure 13 and Figure 14.

"Because of this covid, we can't go back. Can't see my family... After that because I can't go back. Usually when at home, I always help my mother," (S8/2, lines 1-4, 08/10/2020)

"The first one ... homesick. Miss my parents, my home," (S13/2, line 1, 08/10/2020)

"So, when I sit alone, I wonder when this covid will end. When can I go home? I want to go home," (S3/2, lines 6-7, 08/10/2020)

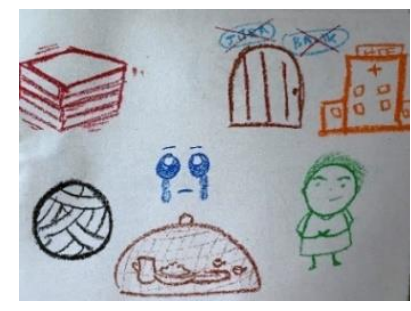

Figure 13. Drawing S8/2, 08/10/2020

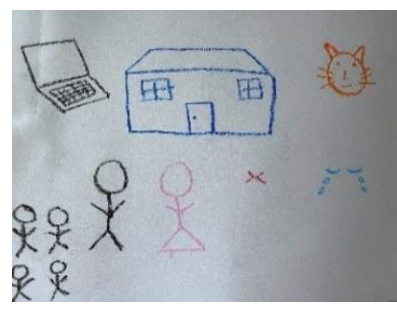

Figure 14. Drawing S3/2, 08/10/2020 


\subsubsection{Financial}

In addition, the study also found that the students also encountered financial problems. Students at ITEM receive an allowance. However, for the new students, the process of managing allowances may take more time. This finding is in line with Matamit, et al. [29] who stated that first-year students also faced financial problems. These financial problems will affect student adaptation. The image of the dompet or wallet drawing represents a symbol relating to students' financial problems as shown in Figure 15.

"The problem I face is not enough money. For anything. I don't want to order food anymore. No more money to order food. Eat...sometimes mee cup... sometimes bread...sometimes biscuits. I told my mother but after that my mother was stressed. My mother gave me money. But I don't want that," (S14/2, line 1-3, 08/10/2020)

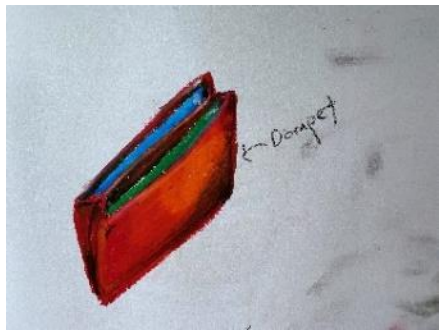

Figure 15. Drawing S14/2, 08/10/2020

\subsection{Interest}

Interestingly, the findings of this study revealed that there were students who pursued their studies at ITEM not because of interest in becoming a teacher. They decided to continue their studies at ITEM to merely fulfil the wishes of their parents who want them to become a teacher. Adaptation problem also occurs when individuals are forced to do something undesirable [33]. Thus, students struggle to adapt to the learning and campus life at ITEM as shown in Figure 16.

"Recently I got an offer to continue my studies in Jordan. I want to go but my mother wants me to study here. So, the situation is stressful. Because my mother really wants me to be a teacher," (S10, lines 2-4, 08/10/2020)

"I do not like it because the results of studying here are not my decisions. But I can't refuse because my parents really like me studying here. So, I can't afford to disappoint my parents. I feel stressed. is my decision to study here correct? When I want to talk to my parents, I can't because my parents want me to study here. (S9, lines 8-13,08/10/2020)

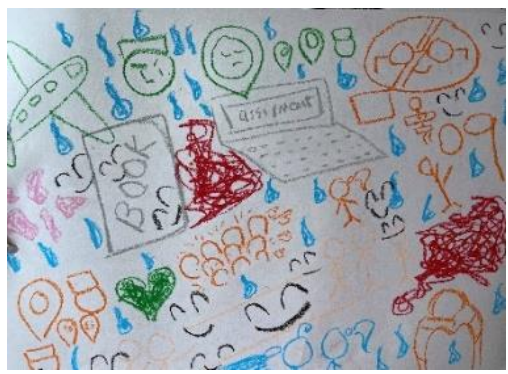

Figure 16. Drawing S10/2, 08/10/2020

The findings of this study seem to be consistent with other research which found that students at ITEM faced difficulties in academic, social, personal and interest. Most first-year students at ITEM experienced difficulties relating to academics and feelings of longing for parents and homes. These difficulties cause their inability to adjust quickly. If they were unable to adapt to the new environment and bounce back from adversity, they would feel stressful and face other psychological problems. The findings of 
the study prove that adaptation problems do not only occur in universities and colleges, but also among students in ITEM who experience adaptation problems. Interestingly, the findings of this study found that there are students who continue their studies in the teaching field to fulfil their parents' wishes wanting them to become a teacher. Meanwhile, using storytelling through drawing approach in this study helped students to express and visualize their experiences during the first month at ITEM. The integration of storytelling and drawing can help students express their experiences and emotions. Previous studies have indicated that the problems can be identified through visualization of the problems [25]. In addition, storytelling through drawing helps counselor or facilitator to understand the experiences students go through and help them to formulate appropriate interventions. Hence, the findings may help us to understand the students' adaptation experiences in the transition phase.

\section{CONCLUSION}

Based on the present study, it can be concluded that the first-year students at ITEM experienced difficulties in adapting to their academic, social, personal and interest that can contribute to stress factors, affect their performance and daily lives. Although there is an orientation week designated for new students, ITEM needs to monitor students who have adjustment problems after a month at ITEM. Through this study, ITEM can get an overview of the difficulties faced by first-year students and prepare appropriate interventions to help the students. Students at the ITEM are trained to be competent and educator-minded teachers. The intention of ITEM is to produce competent and high-quality teachers in line with the Malaysian Teacher Standards which established teacher training centers to produce teachers who are creative and with critical thinking, possess problem solving skills, are able to create new opportunities, have resilience and ability to deal with the ever-changing global education. Thus, the formation of teacher personality starts from the first day of enrolment at ITEM. The initial phase of study is a challenging phase for students as they undergo a transition from secondary school to ITEM. This requires them to adapt to the new environment and culture of ITEM which focuses on the formation of educator-minded teacher personality.

Nonetheless, it is important to note that this research has its own limitations. The findings of this qualitative study are not generalizable to contexts other than ITEM. Further research is needed to explore strategies used by first-year students to cope with the adaptation difficulties in the transition phase. Therefore, it is hoped that the findings of this study can help counselors, lecturers, mentors and administrators at ITEM to provide intervention programmes. It may help first-year students adjust well in the new learning environment and increase the level of students' adjustment at the transition phase and the next phase.

\section{REFERENCES}

[1] R. Arjanggi and L.P.S. Kusumaningsih, "College adjustment of first year students: The role of social anxiety," Journal of Educational, Health and Community Psychology, vol. 5, no. 1, pp. 30-39, 2016.

[2] R.J. Ribbe, et al., "Exploring the Impact of an Outdoor Orientation Program on Adaptation to College," Journal of Experiential Education, vol. 39, no. 4, pp. 355-369, 2016.

[3] H. Elias, S.P. Wong, and M.C. Abdullah, "Stress and academic achievement among undergraduate students in Universiti Putra Malaysia,” Procedia - Social and Behavioral Sciences, vol. 29, pp. 646-655, 2011.

[4] M. Julia and B.Veni, "An analysis of the factors affecting students' adjustment at a University in Zimbabwe," International Education Studies, vol. 5, no. 6, pp. 244-250, 2012.

[5] E. G. Parameswaran and C. Beena, Encyclopedia of psychology. Hyderabad: Neelkamal Publication Pvt. Ltd, 2016.

[6] P.C. Nyamayaro and C.Saravanan, "The relationship between adjustment and negative emotional states among first-year medical students," Asian Journal of Social Science \& Humanities, vol. 2, no. 3, pp. 270-278, 2013.

[7] M. Credé and S.Niehorster, "Adjustment to College as Measured by the Student Adaptation to College Questionnaire :A Quantitative Review of its Structure and Relationships with Correlates and Consequences," Educ Psychol Rev, vol. 24, pp.133-165, 2012.

[8] A. I Clinciu, "Adaptation and Stress for the First Year University Students," Procedia-Social and Behavioral Sciences, vol. 78, pp. 718-722, 2013.

[9] G. Ababu, A. Yigzaw, Y. Besene, and W. Alemu "Prevalence of adjustment problem and its predictors among firstyear undergraduate students in Ethiopian University: A Cross-Sectional Institution Based Study," Psychiatry Journal, vol. 2018, pp. 1-7, 2018.

[10] J.L.Y Terpstra Tong and A. Ahmad, "High school-university disconnect: a complex issue in Malaysia," International Journal of Educational Management, vol. 32, pp. 851-865, 2018.

[11] M.Thuo, et.al., "Transition to university life: insights from high school and university female students in Wolaita Zone, Ethiopia," Journal of Education and Practice, vol. 8, no. 4, pp. 45-54, 2017.

[12] R. Ashwini and P.B. Vijay, "Stress and adjustment among college students in relation to their academic performance," Indian Journal of Health and Wellbeing, vol. 5, no. 3, pp. 288-292, 2014. 
[13] D. Conley, Redefining college readiness. Eugene, OR: Educational Policy Improvement Center, 2011.

[14] A.R.J. Brigs, J. Clark and I. Hall, "Building bridges: understanding student transition to university," Quality in Higher Publication, vol. 18, no. 1, pp. 3-21, 2012.

[15] L. Measor, P. Wilcox, and P. Frame, "Transformation or Trauma: The Transition to Higher Education of Non-Traditional Students," In T. Hinton-Smith, ed., Widening Participation in Higher Education. Issues in Higher Education. Palgrave Macmillan, London, 2012.

[16] M. C. Melendez, "The Influence of Residential Status on the Adjustment to College at Four Urban Universities," Journal of College Student Retention: Research, Theory \& Practice, vol. 20, no. 4, pp. 437-454, 2019.

[17] R. C. Feldt, et al., "Measuring adjustment to college: Construct validity of the student adaptation to college questionnaire," Measurement and Evaluation in Counseling and Development, vol. 44, no. 2, pp. 92-104, 2011.

[18] M. G. Wintre, et al., "Academic achievement in first-year university: who maintains their high school average?" High Educ, vol. 62, pp.467-481, 2011.

[19] A. Horgan, J. Sweeney, L. Behan, and G. McCarthy, "Depressive symptoms, college adjustment and peer support among undergraduate nursing and midwifery students," Journal of Advanced Nursing, vol. 72, no. 12, pp. 3081-3092, 2016.

[20] A.I. Kural and B. Özyurt, "The associations between university adjustment, adult attachment styles, personality traits, and perceived stress," American International Journal of Social Science, vol. 7, no. 2, pp. 43-54, 2018.

[21] J. W. LaBrie, et al., "Poor adjustment to college life mediates the relationship between drinking motives and alcohol consequences: A look at college adjustment, drinking motives, and drinking outcomes," Addictive Behaviors, vol. 37, no. 4, pp. 379-386, 2012.

[22] S. L. Chiam, "Meningkatkan Sikap Resilien Guru Pelatih Dengan Mengguna Sandtray Sebagai Satu Pendekatan Kaunseling," Ph.D Dissertation, Universiti Kebangsaan Malaysia, 2018.

[23] N. Abu Bakar, Z. Mohamed, and S. I. M. Yuso "Model Pencapaian Matematik Berasaskan Penyesuaian Pelajar: Pendekatan Kuasa Dua Terkecil Separa," Jurnal Kurikulum \& Pengajaran Asia Pasifik, pp. 1-12, 2015.

[24] J. Puff, et al., "Depression as a mediator in the relationship between perceived familial criticism and college adaptation," Journal of American College Health, vol. 64, no. 8, pp. 604-612, 2016.

[25] A. Hj. Hasbullah, I. W. Othman, N. M. Suki, Y. M. Safuan, J. Herlina, and R. R. Adie, "Pengalaman tahun pertama pelajar antarabangsa Universiti Malaysia Sabah," Labuan E-Journal of Muamalat and Society (LJMS), vol. 11, pp. 77-85, 2017.

[26] L. Cozolino, The neuroscience of psychotherapy: Healing the social brain, 23rd ed. W W Norton \& Co, 2017.

[27] C.A. Malchiodi, Handbook of art therapy. Guilford Press, 2011.

[28] E. S. Kelley and K. Kinney, "Word Learning and Story Comprehension from Digital Storybooks: Does Interaction Make a Difference?" Journal of Educational Computing Research, vol. 55, no. 3, pp. 410-428, 2017.

[29] N. Matamit, et al., "Teaching challenges on the use of storytelling in elementary science lessons," International Journal of Evaluation and Research in Education (IJERE), vol. 9, no. 3, pp. 716-722, 2020.

[30] V. Braun and V. Clarke, "Using thematic analysis in psychology," Qualitative Research in Psychology, vol. 3, no. 2, pp. 77-101, 2006.

[31] V. Tinto, "Reconstructing the First-year of College," Planning for Higher Education, vol. 25, no. 1, pp.1-6, 1996.

[32] S. Zhang, et.al, "Relationships between social support, loneliness, and internet addiction in Chinese postsecondary students: A longitudinal cross-lagged analysis," Front. Psychol, vol. 9, 2018.

[33] A. A. Orlov, S. V. Pazukhinab, A. V. Yakushinc, and T. M. Ponomarevaa, "A study of first-year students' adaptation difficulties as the basis to promote their personal development in university education," Psychology in Russia: State of the Art, vol. 11, no. 1, pp. 71-83, 2018. 